\title{
Semiotyczne aspekty przekazu digitalnego. U podstaw literatury cyfrowej*
}

\begin{abstract}
Szczęsna Ewa, Semiotyczne aspekty przekazu digitalnego. U podstaw literatury cyfrowej [Semiotic aspects of digital text. The base of digital literature]. „Przestrzenie Teorii" 24, Poznań 2015, Adam Mickiewicz University Press, pp. 49-71. ISBN 978-83-232-2892-7. ISSN 1644-6763. DOI 10.14746/pt.2015.24.3.

This paper focuses on the influence of the semiotic organization of the digital message on the creation of aesthetic meanings in digital art. It presents modifications in the sphere of text presentation and focuses on functions that it play in creation of literary meanings. Moving, sound created, changing shape and color texture is the place of creation of meanings as well as the interaction of the semantic of the texture and the semantic of words. New digital tools, e.g. programming, the interface are important part of new semiotic code that shapes literature (e.g. linking facilitates the creation of new forms of plots, the interface is a part of literary discourse, the cursor is both the medium of meanings and the tool of text working). The paper concludes that digital technologies redefine the ontology of the literary text and art discourse.
\end{abstract}

\section{Technologiczne uwarunkowania znaku, tekstu i dyskursu. Oprogramowanie a ramy semiotyczne tekstu}

Pod względem zdolności do uczestnictwa w tworzeniu nowych form tekstowych, gatunkowych, dyskursywnych cyfrowość jest jednocześnie rewolucyjna i ewolucyjna. Jej rewolucyjność znajduje odzwierciedlenie w społecznym odczuciu gwałtownych przemian w sferze sposobu obchodzenia się czy użytkowania przestrzeni informacji, komunikacji, estetyki: znoszeniu granic między dyskursami w efekcie ich cyfrowej adaptacji, swobodzie łączenia dziedzin, przechodzenia z jednej formy aktywności na inną; wytwarzaniu nowych gatunków tekstowo-komunikacyjnych. Z kolei ewolucyjny charakter cyfrowości uwidocznia się w akcie wpisywania się przekazu digitalnego $\mathrm{w}$ proces przemian tekstowych, technologicznych i szerzej kulturowych. Każda forma tekstowa i komunikacyjna w świecie digitalnym, każde narzędzie oprogramowania znajduje swoje zapowiedzi (wersje pierwotne, pre-reprezentacje) w przedcyfrowym świecie tekstowym. Zupełnie tak, jakby cyfrowość uwalniała struktury tekstowe i dyskursywne hamowane przez dotychczasowe technologie, pozwalała

* Artykuł powstał w ramach grantu „Znakowe wartości kultury. Aspekty historyczne, tożsamość i zmiana” (11H11020280), afiliowanego przy Instytucie Badań Interdyscyplinarnych Uniwersytetu Warszawskiego. 
im swobodnie się rozwijać, a niekiedy wręcz zdominować formy dotychczasowe.

Dobrego przykładu dostarcza tu link, który jest narzędziem strukturowania tekstu $\mathrm{w}$ przekazach hipertekstowych. $\mathrm{Z}$ jednej strony wpisuje się on w myślenie asocjacyjne, obecne w takich zabiegach tekstowych, strukturach myślenia i sposobach organizowania tekstu jak: narracja strumienia świadomości, metafora, intertekstualność czy przypisy, stanowiąc kolejny przykład tekstowej realizacji skojarzeniowej formy myślenia. Z drugiej strony, wyznaczając specyfikę przekazu cyfrowego, link przemodelowuje myślenie o tekście. Oto bowiem tekst staje się formą otwartą, której początek i koniec, a także przebieg, wyznaczane są w efekcie dokonywanych przez użytkownika wyborów. Modyfikacji ulega sposób konstruowania znaczeń - linkowanie oznacza tworzenie tekstu z elementów należących do różnych pól tekstowych, wiąże się z nieustanną rekontekstualizacja tekstu, co ma istotny wpływ na kreowanie znaczeń. Linki wreszcie - jak pisze Nicholas C. Burbules - „same tworzą znaczenia, są czymś więcej niż obojętnym środkiem przechodzenia od punktu A do punktu B"1, zaś powtarzalność określonych typów powiązań prowadzi do wytworzenia nawyków myślowych - może na przykład oznaczać stereotypizację porządku myślenia w procesie użytkowania Internetu.

W prozie hipertekstowej rozmaite sposoby linkowania służą wytwarzaniu różnych modeli fabuł - decydują o kształtowaniu się odmian gatunkowych hipertekstu literackiego ${ }^{2}$. Link należący do sfery tekstu i dyskursu w sztuce hipertekstowej może być znaczącym elementem tekstowym, kształtującym w sposób intencjonalny znaczenia. W utworze hipertekstowym Czarne jagody Susan Gibb ${ }^{3}$ fioletowa barwa słów-linków jest znakiem okaleczonej psychiki bohaterki (molestowanej w dzieciństwie). Przejście przez mające fioletową barwę zlinkowane słowo do następnego pola tekstowego jest przejściem przez perspektywę poznawczą postaci, filtrem trudnym do usunięcia jak bolesne wspomnienia zdarzeń i jak ślady na ubraniu po jagodach. Lektura hipertekstowa jest tu nie tylko odczytywaniem tekstu, ale i sensorycznym doświadczaniem psychiki bohaterki. Kiedy użytkownik najeżdża kursorem na zlinkowane słowo,

1 N.C. Burbules, Retoryka sieci: hiperlektura oraz krytyczny poziom piśmienności, przeł. J. Mach, [w:] Ekrany piśmienności. O przyjemnościach tekstu $w$ epoce nowych mediów, red. A. Gwóźdź, Warszawa 2008, s. 202.

2 Modele te przedstawia Mariusz Pisarski, zob. M. Pisarski, Nowe media - nowe opowieści? Fabułotwórczy potencjat struktur hipertekstowych, [w:] Przekaz digitalny. Aspekty semiotyczne, semantyczne i komunikacyjne, red. E. Szczęsna, Kraków 2015.

3 S. Gibb, Czarne jagody, hipertekst, przeł. M. Pisarski, Kraków 2011. Zob. <http:// www.ha.art.pl/hiperteksty/czarne_jagody/czarne_jagody.html>. 
fioletowa barwa zmienia się na czerwoną ${ }^{4}$ (czerwień to między innymi symbol ciała ludzkiego, nieposkromionej chuci, pożerającej potęgi, cierpienia, zbrodni, to barwa $\mathrm{krwi}^{5}$ ) - oddając traumatyczność doświadczeń - barwa znów jest znakiem okaleczonej przeszłością perspektywy poznawczej, w której się znajdujemy, która jest jedyną perspektywą udostępniającą nam „tu” i „teraz” oraz „tam” i „wówczas” świata bohaterki. Kliknięcie na link - poznanie wspomnienia, odczuć, przeżyć postaci skutkuje blaknięciem tego linku (zlinkowane słowo zostaje odznaczone na bladosiny kolor) - co znów stanowi analogię do motywu fabularnego - pragnienia kobiety, by wymazać wspomnienia z pamięci. W sferze zdarzeń fabularnych znakiem symbolicznym tego pragnienia jest akt zamalowania na biało ścian wystawy - na których bohaterka (w życiu dorosłym jest malarką) namalowała jagody oraz symboliczny akt rozebrania się - pragnienie „wtopienia” się w biel ścian - zatopienia w niepamięci.

Przywołany przykład prozy hipertekstowej pokazuje, że elementy interfejsu - funkcjonujące w Internecie na stronach informacyjnych jako narzędzia komunikacji - a więc należące do sfery dyskursu, w przestrzeni sztuki hipertekstowej mogą być integralnymi składnikami tekstu - współtworzyć znaczenia tekstowe. W Czarnych jagodach barwa zlinkowanych słów nie jest jedynie sposobem zaznaczenia faktu linkowania (nie jest wyłącznie elementem interfejsu), ale wpisuje się w kreowanie znaczeń fabularnych.

Przykład linku ilustruje i potwierdza znaczący udział technologii w kreowaniu kodów semiotycznych, które same nie są tekstami, ale bez których tekst nie może się obyć. Technologie wyznaczają organizację semiotyczną tekstów - odmienną w przypadku tekstów drukowanych, audialnych, audiowizualnych czy wreszcie digitalnych. Kreują układy znaków specyficznych, różnicujących media-nośniki (np. książkę, telewizję, komputer) oraz media-formy tekstowe (literaturę, program telewizyjny, Internet). Znajdują się u podstaw krystalizowania się najrozmaitszych gatunków medialnych, a w ich obrębie konkretnych realizacji tekstowych.

Ramy semiotyczne medium - to, jakimi znakami posługuje się dane medium, oraz to, jakimi znakami posługują się media konkurencyjne stymulują rozwój struktur tekstowych i stylów artystycznych. Wielowiekowy brak możliwości posłużenia się ruchomym, udźwiękowionym obrazem sprzyjał niewątpliwie rozwojowi sztuki literackiej (np. ciągłemu wzbogacaniu literackich form opowiadania i opisu), pojawienie się foto-

\footnotetext{
${ }^{4}$ Dotyczy to polskiej wersji hipertekstu autorstwa Mariusza Pisarskiego.

${ }^{5}$ Zob. np. W. Kopaliński, Stownik symboli, Warszawa 1990, s. 55.
} 
grafii przyspieszyło rozwój malarstwa nieprzedstawiającego. Analogicznie, chęć oddania wieloperspektywiczności oglądu w malarstwie czy przeżyć wewnętrznych bohatera w filmie służyły ewolucji języków tych sztuk. Oznacza to, że zarówno ograniczenia semiotyczne danego medium, jak i jego możliwości (a więc własności znakowe), pobudzają inwencję artystyczną, stymulują rozwój form artystycznych i szerzej - tekstowych.

Podobnie jest $\mathrm{w}$ przypadku technologii cyfrowych: ramy semiotyczne przekazów generowanych cyfrowo inspirują tworzenie nieobecnych w zastanej kulturze form medialnych, gatunków tekstowych oraz rozwiązań w sferze organizacji konkretnych tekstów. Co więcej, odmienne własności semiotyczne wymagają odmiennych form percepcji, a tym samym stwarzają nowego odbiorcę i ustanawiają na nowo sytuację komunikacyjną. W efekcie dochodzi do wykształcania się form dyskursywnych, które rzutują na sposób istnienia zastanej rzeczywistości kulturowej, na rozumienie świata rzeczy i świata znaków już istniejących. Modelując znaki, technologie cyfrowe modelują też nasze myślenie i sposób poznawania świata.

Przekaz cyfrowy - słowny, ikoniczny, dźwiękowy - nie modeluje nośników materiałowych (jak np. rzeźba czy malarstwo), choć potrzebuje materialnych urządzeń technicznych (hardware) umożliwiających stworzenie dla przekazu cyfrowego środowiska (software), w którym przekaz ten może zaistnieć. Środowiska te są ciągiem powiązanych logicznie poleceń sterujących pracą komputera (programy systemowe), wspomagających prace programisty (kompilatory) czy wreszcie przeznaczonych bezpośrednio dla użytkownika (aplikacje). Dostęp do nich użytkownika, wchodzenie $\mathrm{w}$ interakcje $\mathrm{z}$ programem możliwe są dzięki pośrednictwu interfejsu - tu zwłaszcza interfejsu graficznego, czyli sposobu, w jaki informacja prezentowana jest na ekranie komputera.

Aplikacja, czyli oprogramowanie użytkowe, jest środowiskiem tekstowym i komunikacyjnym, w którym znaki łączone są w specyficzny dla niego sposób. Szukając analogii w świecie dotychczasowej kultury, można by odwołać się do świata dyskursów, np. sztuki, polityki, ekonomii, prawa, religii i wielu innych, które również są środowiskami tekstowymi (kreują specyficzne dla siebie klasy tekstów) i komunikacyjnymi, systemami rozwijającymi się w czasie, rządzącymi się właściwymi sobie prawami. Zasadnicza różnica polegałaby na tym, iż podczas gdy wspomniane systemy kształtowały się na przestrzeni wielu wieków i niejako oddolnie - wykrystalizowały się w efekcie określonych typów zachowań społecznych i tekstowych, systemy wykreowane w technologiach cyfrowych zaprojektowane zostały w stosunkowo krótkim czasie i w sposób odgórny przez wąską grupę specjalistów (informatyków). 
Program jest zaprojektowanym kodem tworzonym w ramach globalnego języka formatowania, czy też języka znaczników, jakim jest html. Dysponuje specyficznym dla siebie zasobem znaków i regułami ich wiązania. Zarówno zasób znaków, jak i skala możliwości ich łączenia są zmienne - mogą ulegać modyfikacjom w kolejnych wersjach programu. Specyficzne dla danego programu struktury umożliwiają generowanie właściwej temu programowi klasy tekstów - gatunków, form tekstowych (np. edytory tekstu umożliwiają tworzenie plików tekstowych, arkusze kalkulacyjne - tabel, zestawień; programy graficzne - obrazów, programy do prezentacji - prezentacji, fotograficzne i filmowe - edycję filmu i fotografii). Modyfikowanie tych form tekstowych przez użytkownika może dokonywać się tylko w ramach tego, co zostało zaprogramowane, wyjście poza te granice jest możliwe tylko wówczas, gdy zostanie ono uwzględnione przez twórców programu w kolejnej jego wersji.

Program - w swej jednostkowej realizacji - jest propozycją kodu, a - jak zauważa Umberto Eco - „propozycja kodu to propozycja pewnej korelacji”, korelacje zaś są zazwyczaj „ustanawiane przez konwencję"7. W przypadku kodów komputerowych zarówno o korelacjach, jak i konwencji decydują twórcy programów ( $\mathrm{z}$ uwzględnieniem potrzeb użytkowników). W efekcie rozwój form tekstowych dokonuje się w ramach arbitralnych, wyznaczonych przez specjalistów z dziedziny technologii cyfrowych strategii dyskursywnych. Poddane technologizacji reguły tworzenia tekstu, mechaniczność kodu, nadto brak materialności znaku pozwalają na automatyczną reprodukcję nie tylko tekstu, ale i reguł jego tworzenia. Może być to bardzo przydatne w takich dyskursach jak choćby dyskurs ekonomii. Jednak te same właściwości mogą budzić niepokój w zetknięciu z dyskursem sztuki, rodzić pytanie, czy mechaniczność ko$\mathrm{du}$, reprodukcja struktur nie stanowią zagrożenia dla oryginalności. Odpowiedzi na to pytanie dostarcza na przykład Vilém Flusser, według którego praktyka artystyczna w środowisku digitalnym powinna opierać się na przełamywaniu norm generowanych przez komputer, zejściu z wytyczonego toru, na grze zmuszającej maszynę do wytworzenia czegoś nieprzewidywalnego ${ }^{8}$. Elementem takiej gry jest też wyzyskanie interfejsu do celów artystycznych, na przykład ich utekstowienia, nadania im jednorazowych znaczeń, tekstowego ich sfunkcjonalizowania, jak dzieje się to w literaturze hipertekstowej.

${ }^{6}$ U. Eco, Teoria semiotyki, przeł. M. Czerwiński, Kraków 2009, s. 201.

7 Ibidem.

8 Zob. V. Flusser, Ku filozofii fotografii, przeł. J. Maniecki, Katowice 2004. 


\section{Znaki interfejsu. Kursor jako wieloznak digitalny}

Oprogramowanie wyznacza zarówno ramy gatunkowe przekazu, jak i ramy komunikacyjne, tekstowe i znakowe. Ustanawia powtarzalną (w obrębie danego programu) strukturę przekazu, która znajduje odzwierciedlenie $\mathrm{w}$ warstwie semiotycznej tego, co użytkownik widzi na ekranie. Najogólniej rzecz ujmując, są to: pole tekstowe (strefa tekstu) oraz pole narzędzi tekstowych (strefa obsługi tekstu - interfejs), które umożliwiają użytkowanie tekstu - a więc na przykład kreowanie go, modyfikowanie, przemieszczanie się jednego tekstu do innego (co oznacza rekontekstualizację, a w efekcie reinterpretację znaczeń). Posłużenie się narzędziami interfejsu prowadzi do dyskursywizacji tekstu - każdy sposób komunikacyjnego użycia tekstu zakotwicza go bowiem w dyskursie.

Mianem interfejsu określa się zarówno wszelkie urządzenia sprzętowe (np. myszkę, klawiaturę), jak i elementy oprogramowania (interfejs graficzny), które pośredniczą między użytkownikiem a komputerem umożliwiają realizowanie określonych zadań tekstowych i komunikacyjnych, organizują przestrzeń tekstową przy użyciu systemu komputerowego (informatycznego) ${ }^{9}$.

Analiza tekstowa i dyskursywna przekazu digitalnego na plan pierwszy każe wysunąć interfejs graficzny, który scharakteryzować można jako swoistą nakładkę $\mathrm{z}$ informacjami na temat tekstu oraz narzędziami umożliwiającymi działania na tekście. Znaczenie interfejsu graficznego i konstytuujących go ikon realizuje się w możliwości przekształcania tekstu, dokonywaniu operacji tekstowych. Elementy interfejsu nie należą bezpośrednio do świata tekstu, choć zawarta jest w nich potencja kształtowania go - niemal każde działanie tekstowe użytkownika angażuje interfejs. Należą natomiast do świata dyskursu jako te, które uczestniczą w użytkowaniu tekstu - wpisują go w sytuację komunikacyjną.

Interfejs nie jest tekstem, choć służy tekstowi. Jest zestawem ikonicznych i słownych narzędzi i informacji tekstowych, strukturą meta nadbudowaną nad tekstem, znajdującą się poza nim, ale odnoszącą się bezpośrednio do niego, warunkującą jego modelowanie i przekształcającą go w dyskurs. Zaznacza zwykle swoją osobność, odrębność wobec świata tekstu, czemu sprzyjają: ikoniczna struktura, powtarzalna kompozycja (pasek nad tekstem, pod tekstem, elementy zaznaczone fluorescencyjnie, powtórzenia intersemiotyczne - ikonie odpowiada parafraza słowna zamieszczona pod ikoną lub pojawiająca się po najechaniu kursorem na

${ }^{9}$ Zob. L. Kuźniarz, M. Piasecki, Zarys obiektowej metodologii analizy i projektowania multimedialnego interfejsu użytkownika, <http://www.ii.pwr.wroc.pl/ piasecki/publications /kuzniarz_piasecki_MiSSI-98.pdf>. 
ikonę). Wyznacza nie tylko fakt i sposób uobecnienia się tekstu, ale także ramy działań na tekście; umożliwia konstruowanie topografii tekstu, która, jako modelowana przez użytkownika, jest w stanie ciągłego stawania się ${ }^{10}$.

W sposobie istnienia interfejsu ścierają się dwie przeciwne tendencje. $\mathrm{Z}$ jednej strony jest to tendencja do zaznaczania swojej osobności wobec świata tekstu, ukazywania się jako zestaw poręcznych i podręcznych narzędzi umożliwiających użytkownikowi dostęp do tekstu, zarządzanie nim, powodowanie go. Czynnikami, które wzmacniają tę tendencję, są: różnorodność programów (i ich jednostkowych interfejsów) oraz ciągłe ich modernizacje - nowe wersje programów zawierają nowe wersje interfejsu. Z drugiej strony powtarzalne cechy interfejsu - ikoniczna struktura, stała w obrębie danego programu lokalizacja na ekranie komputera, funkcja semantyczna ikon realizująca się w syntaktyce - relacjach, w jakie wchodzą z polem tekstu - prowadzą do jego transparentności.

Elementem interfejsu graficznego jest kursor, który przez użytkowników komunikacji digitalnej definiowany jest jako oznacznik. Pytanie o ontyczność i status kursora jest pytaniem o jego znakową istotę. Zdefiniowanie znaku jako postrzeganego zmysłowo (wzrokiem, dotykiem, słuchem) bytu (np. wygląd, przedmiot, czynność), który w sposób intencjonalny, na mocy konwencji wskazuje na coś, zastępuje coś, odnosi się do czegoś poza sobą (transcendencja znaku), pozwala dostrzec cechy znaku $\mathrm{w}$ kursorze. Postrzegany jest on bowiem zmysłowo, ustanawiany i odczytywany w sposób umowny, odnosi się do czegoś poza sobą. Specyficzną cechą kursora jest to, że nazwą tą obejmuje się różne przedstawienia (czy klasę przedstawień), pełniące jednak określoną funkcję w świecie dyskursu digitalnego, zaś wskazywanie, odnoszenie się dotyczy działania na tekście ( $\mathrm{w}$ ramach danego dyskursu). Jako taki kursor wpisuje się w poczet znaków woli działania. Tak jak np. podanie ręki wiąże się z działaniem i jest znakiem określającym wolę przywitania się, włączenie kierunkowskazu - woli skręcenia w daną stronę, tak też kursor wiąże się z działaniem ustawiania i kliknięcia (zaznaczenia), które wyraża i realizuje wolę dokonania określonej, przypisanej do danego kursora i programu operacji tekstowej. Pod tym względem kursor w świecie dyskursu digitalnego nie różni się wiele od znaku w kulturze, kiedy to ten sam znak (np. gest, zachowanie) może być zupełnie różnie interpretowany w zależności od kręgu kulturowego, w którym zostaje użyty11.

${ }^{10}$ N.K. Hayles, Stan wirtualności, przeł. J. Mach, [w:] Ekrany piśmienności..., s. 256.

11 Najrozmaitsze przykłady różnego odczytywania tych samych zachowań w różnych kręgach kulturowych (europejskim, amerykańskim, japońskim, arabskim) analizuje porównawczo Edward T. Hall. Zob. E.T. Hall, Ukryty wymiar, przeł. T. Hołówka, Warszawa 1997. 
Kursor wykracza poza tradycyjne rozumienie znaku jako tego, co „wskazuje na”, „odnosi się do”. Wskazywaniu na jakieś działanie towarzyszy bowiem możliwość jego uruchomienia. W literaturze hipertekstowej kursor jest narzędziem umożliwiającym dzianie się tekstu. Kliknięcie słowa „start”, „rozpoczęcie” uruchamia zdarzenie tekstowe; wybieranie i przesuwanie elementów tekstowych służy ustanawianiu świata przedstawionego, buduje fabułę, inicjuje bieg zdarzeń.

A zatem kursor jest typem znaku, który odnosi się do tekstu w sposób narzędziowy - umożliwia przeprowadzenie określonych operacji na tekście. Jest z tekstem digitalnym ściśle związany i wyznacza jego specyfikę, ale przynależy do świata dyskursu. Specyfikę kursora wyznaczają: wielopostaciowość warstwy przedstawień (znak, w który wpisana jest możność bycia różnym znakiem - zmiany warstwy wyrażania, znaczenia, zakresu działań proponuję opisywać jako wieloznak), realizowanie się znaczenia w gotowości do przeprowadzenia działań tekstowych i dyskursywnych w wyniku zaznaczenia (kliknięcia) danego elementu tekstowego (stąd kursor nazywany jest oznacznikiem) oraz charakterystyczne dla narzędzia przeprowadzenie tych działań.

Kursor jako wytwór mediów cyfrowych określa ich specyfikę. Mieści w sobie funkcję wskazywania na dyskurs, którego jest elementem - jego obecność oznacza dla użytkownika uczestnictwo w dyskursie digitalnym. Jednocześnie jest znakiem korzystającym $\mathrm{w}$ warstwie przedstawień w znacznej mierze ze znaków konwencjonalnych kultury zastanej (np. strzałka), choć również kreującym własne przedstawienia oraz dokonującym przesunięć w znaczeniach znaków zaadoptowanych. Nadawanie kursorowi postaci graficznej znaków już funkcjonujących w kulturze i możliwie uniwersalnych (np. wspomniana już strzałka jako znak wskazywania na coś, pokazywania, kierunku) sprzyja zakotwiczeniu go w kulturze, łatwiejszej asymilacji nowych użyć znaku.

Dyskurs digitalny reinterpretuje adaptowane znaki, wiążąc je z działaniami na tekście. W przypadku strzałki wielość możliwych działań sprawia, że kursor jako znak staje się transparentny znaczeniowo, bardziej istotne niż wskazywanie na coś staje się działanie; funkcja narzędzia dominuje nad funkcją oznaczania czy odnoszenia. Tak jest zwłaszcza w przypadku tych kursorów, których postać graficzna i funkcja poddane zostają uniwersalizacji - są popularne, wspólne dla wielu różnych programów.

Funkcja odnoszenia, wskazywania na jakieś znaczenie zaznacza się silniej w przypadku kursorów wytwarzanych na potrzeby jednego dyskursu (jak dzieje się to często w przypadku gier wideo, czy literatury grywalnej). Jednak i w tym przypadku twórcy programów nadają kurso- 
rom zazwyczaj taki wygląd, który pozwala graczowi łatwo domyślić się znaczenia znaku i jego możliwości jako narzędzia działań. Tak bywa w przypadku przedstawień, które wchodzą ze znaczeniem i działaniem $\mathrm{w}$ relację synekdochy czy metonimii. Kursor przybierający w literaturze grywalnej postać długopisu wskazywać będzie na możliwość dopisania czegoś, kursor w kształcie otwartych drzwi informuje o możliwości przejścia do innego pomieszczenia, kursor w kształcie zwróconych do siebie masek informuje o możliwości rozmowy np. z napotkaną postacią. Wyglądy kursorów odnoszą się do rzeczywistości społecznej, co służy zacieraniu granicy między światem przedstawionym - światem fikcji a światem rzeczywistości fizykalnej.

Kursor nie występuje w tym samym zakresie we wszystkich formach i przejawach komunikacji digitalnej. Jest odwzorowaniem na wyświetlaczu ruchu myszki lub ruchu palców po płaszczyźnie sensorycznej klawiatury (towarzyszy też wybieraniu znaków z klawiatury - znak pionowej kreski). Sygnalizuje miejsce, w którym użytkownik może podjąć działania, a także określa rodzaj tych działań. Pomijany lub redukowany bywa tam, gdzie działanie użytkownika sprowadza się do aktu wyboru - bez dokonywania operacji na tekście (np. w telefonach komórkowych, GPSach, czytnikach e-booków, aparatach cyfrowych). Dotykowe interaktywne ekrany znoszą kursor lub wyraźnie ograniczają zakres jego form obecności. W efekcie nieustanny rozwój technologii cyfrowych zmierzający do możliwie maksymalnego wyeliminowania sprzętów pośredniczących między użytkownikiem i tekstem sprawia, że kursor staje się znakiem-narzędziem w zaniku.

Kursor jest znakiem wielopostaciowym, wielofunkcyjnym, którego znaczenie realizuje się $\mathrm{w}$ działaniu. Wielopostaciowość oznacza, że tą samą nazwą obejmuje się znaki, które w różnych programach, w różnych miejscach na płaszczyźnie ekranu mogą mieć odmienny wygląd i które pełnią odmienną funkcję szczegółową w danym dyskursie. Z formą, jaką przyjmuje kursor, wiąże się jego gotowość do podjęcia określonych działań. Jako taki jest to znak, który inicjuje dyskurs, zaprasza użytkownika do kierowania światem tekstu za swoim pośrednictwem. W powiązaniu z działaniem użytkownika kursor ma zdolność oznaczania (zaznaczania) znaków tekstowych (słów, obrazów) i przeprowadzania działań na tekście. W tym ostatnim przypadku staje się narzędziem, przy użyciu którego użytkownik może wybierać i wykorzystywać inne narzędzia interfejsu graficznego do działań tekstotwórczych czy komunikacyjnych.

Niezależnie od możliwych form graficznych i funkcji szczegółowych wszystkie odmiany kursora mają te same cechy wspólne, pełnią te same funkcje globalne, co sprawia, że użytkownik bez trudu rozpoznaje kursor 
także w nowych dyskursach digitalnych bez względu na to, czy zna już dany program, czy też nie. Cechy te wyróżniają kursor spośród innych znaków digitalnych, stanowiąc o jego swoistości. Są to: mobilność, którą zarządza użytkownik, funkcja działania (bycie znakiem/narzędziem tekstowym), powiązanie wyglądu i funkcji kursora $\mathrm{z}$ miejscem na ekranie (przesunięcie kursora $\mathrm{z}$ pola tekstu na pole paska narzędzi wiąże się ze zmianą wyglądu kursora i jego możliwości jako narzędzia działań) i działaniem użytkownika (np. kliknięcie jednokrotne a dwukrotne zmienia działanie), przynależność do dyskursu (nie zaś tekstu).

\section{Semiosfera digitalna - istota i własności}

Kategoria semiosfery, definiowana przez Jurija Łotmana jako przestrzeń semiotyczna właściwa danej kulturze ${ }^{12}$, w odniesieniu do przestrzeni digitalnej nazywa znaki i ich organizację właściwą mediom digitalnym. Cechą wyznaczającą specyfikę semiosfery digitalnej jest jej dwupoziomowość (poziom użytkowania i poziom programowania) oraz wielodyskursywność (istnienie podsemiosfer - każdy typ dyskursu digitalnego wyznacza specyficzny dla siebie zestaw znaków i właściwą sobie ich organizację).

Właściwością semiosfery digitalnej jest też jej nieprzerwana ewolucyjność, zmienność wynikająca z postępu technologicznego - nieustannego udoskonalania sprzętów - nośników, które przestają być wyłącznie nośnikami, a stają się kreatorami przekazów oraz programów umożliwiających wytwarzanie określonych form tekstów. Zmienność ta różni się od zmienności w innych nośnikach tekstów. W przypadku książki czy nawet kina można mówić o skokowych zmianach, które wyznaczały nową erę medium: książka pisana, książka drukowana; film niemy, dźwiękowy, chromatyczny, 3D. Okresy pomiędzy nimi są okresami względnej stabilizacji czy udoskonalenia nowej technologii (dźwięk stereo, film szerokoekranowy); nie przynoszą zasadniczych zmian semiosfery. Widoczne jest to zwłaszcza w przypadku książki drukowanej, o której Wojciech J. Burszta pisze, iż jest w zasadzie „[...] niezmienna, nie da się jej unowocześnić, podobnie jak nie da się zreformować samej praktyki czytania. Tym samym jest ona działalnością konserwatywną, idącą pod prąd głównego nurtu konsumeryzmu"13. Zmiana kroju czcionki, zmiana technik

12 J. Łotman, Uniwersum umystu. Semiotyczna teoria kultury, Gdańsk 2008, s. 199.

13 W.J. Burszta, Książka i czytanie $w$ popkulturowym reżimie symultaniczności, [w:] Gadżety popkultury. Społeczne życie przedmiotów, red. W. Godzic, M. Żakowski, Warszawa 2007, s. 139 . 
ilustracyjnych, formatu, rodzaju papieru nie mają wpływu na samą istotę książki, która jest niezmienna. Inaczej jest w przypadku semiosfery digitalnej, która jest w stanie nieustannej reformy; jest wręcz wyznaczana przez rozwój technologii. Nowe programy użytkowe ustanawiają nowe semiosfery.

Digitalna przestrzeń semiotyczna ma charakter dwupoziomowy. Informacja tekstowa na poziomie użytkowania ma swój odpowiednik znakowy na poziomie programowania. Aspekty semiotyczne obu poziomów nie są tożsame. Semiotykę poziomu użytkowania tworzą przedstawienia słowne, ikoniczne, dźwiękowe, liczbowe, mieszane. Są to przedstawienia znane odbiorcy z mediów i dyskursów dobrze osadzonych w kulturze jeszcze przed epoką cyfrową. Media digitalne adaptują całą zastaną semiotyczność tekstową, dokonując jednocześnie jej reinterpretacji - zmieniając materię dotychczasowych znaków i tekstów. Wartość semiotyczna tekstu na poziomie użytkowania zaczerpnięta została $\mathrm{z}$ dotychczasowej kultury. Wartością dodaną jest zmiana w sferze materii znaku - można tu mówić o cyfrowej teksturze, u podstaw której znajduje się niematerialna materia wspólna dla wszystkich form przedstawień, umożliwiająca łączenie, przekształcanie, reinterpretowanie wszelkiego typu znaków, tekstów i dyskursów.

Aspekt semiotyczny znaku i tekstu na poziomie programowania jest mniej zróżnicowany niż na poziomie użytkowania. Mamy tu do czynienia z plikiem tekstowym opisującym - definiującym teksty (ich przedstawienia, układ względem innych znaków, tekstów, charakter - np. linki) na poziomie użytkowania. Wygląd znaku (sposób jego ukazywania się) podporządkowany jest tu całkowicie pragmatyce komunikacji cyfrowej. A ponieważ użyteczność znaku na tym poziomie realizuje się w definiowaniu znaków na poziomie użytkowania, sposobem jego istnienia rządzi zasada wystarczalności. Znaczenie znaku na poziomie programowania realizuje się w relacji, w jaką wchodzi ze swoim odpowiednikiem na poziomie użytkowania - a jest to relacja opisu, definiowania. Co więcej, informacja na temat znaku, który widzimy na ekranie komputera, na poziomie programowania jest rozproszona (zwykle osobno definiowana jest podstawowa wartość znaku, osobno opisywane są jego cechy).

Elementy wyglądu znaku na poziomie programowania, takie jak np. barwa czcionki oraz elementy kompozycyjne (np. kompozycja wersów), nie mają znaczenia dla poziomu użytkowania. Są nośnikami cech drugorzędnych, ale nie w odniesieniu do znaczenia znaku, lecz $\mathrm{w}$ odniesieniu do pragmatyki użycia znaku i tekstu w procesie projektowania, programowania poziomu użytkowania (są to umowne, ustalone przez programistę cechy zapisu, które pozwalają mu na szybkie orientowanie się w tekście np. w sytuacji powrotu do tekstu w celu dokonania jego aktualizacji). 
Semiosferę na poziomie użytkowania i na poziomie programowania łączy relacja reprezentacji semantycznej. Znaki na obu poziomach - ich formy przedstawień, sposoby łączenia, funkcje - różnią się od siebie tak, że w zasadzie można mówić o dwóch różnych podsemiosferach jednej semiosfery digitalnej czy dwóch typach kodów semiotycznych. Jednocześnie każdy znak na poziomie użytkowania ma swoją reprezentację znakową na poziomie programowania (lub też kilka reprezentacji); reprezentacje te tworzą tę samą informację tekstową, co więcej - są ze sobą nierozerwalnie związane (zmiana znaku na jednym poziomie oznacza zmianę $\mathrm{w}$ semiosferze na drugim).

Możliwość zmian dokonywanych w semiosferze na poziomie użytkownika jest ograniczona. Dotyczy tylko tego, co zostało zaprojektowane na poziomie programowania jako możliwe do modyfikacji przez użytkownika. I tak np. to, iż w Wordzie na poziomie użytkowania można wpisać tekst, przekształcać go, nie można natomiast w paskach narzędzi dodać ikon lub zmienić ich wyglądu, wynika $\mathrm{z}$ faktu uwzględnienia i zaprojektowania danej skali możliwości działań użytkownika. Z kolei zmiany na poziomie programowania są nieograniczone i dotyczyć mogą zarówno sfery tekstu, jak i sfery jego obsługi. Oznacza to, że każdy znak wprowadzony przez użytkownika istniał $\mathrm{w}$ formie potencjalnej na poziomie programowania - zaprogramowana została możliwość jego zaistnienia. Jednocześnie trzeba zaznaczyć, że zmiany dokonywane na obu poziomach wymagają odmiennych kompetencji - $\mathrm{z}$ jednej strony jest to znajomość języka programowania, z drugiej kompetencja w sferze komunikacji digitalnej.

Ponieważ media cyfrowe są mediami komunikacji społecznej i jako takie tworzone są i rozwijane ze względu na potrzeby użytkownika, należy uznać poziom użytkowania za podstawowy, a jednocześnie uwarunkowany poziomem programowania i przez niego wytwarzany. Wprawdzie użytkownik wie o istnieniu poziomu programowania (może go zresztą podejrzeć), tak samo jak wie o istnieniu wewnętrznej maszynerii komputera, ale w praktyce, w znakomitej większości przypadków, nie interesuje się nimi. Pod tym względem odbiór mediów digitalnych nie różni się wiele od postrzegania przedmiotów w ogóle. Rudolf Arnheim, rozważając zagadnienie odbioru niewidocznych elementów przedmiotów, pisze:

Większość tego, co wiemy o niewidocznych wnętrzach przedmiotów, jawi się nam jako przyjmowane w dobrej wierze cechy ich zewnętrznego wyglądu. [...] Wzrokowe doświadczenia $\mathrm{z}$ przeszłości sytuują się $\mathrm{w}$ stosownych miejscach mojego obecnego pola percepcyjnego, pożytecznie je uzupełniając. [...] W istocie wiele przedmiotów codziennego użytku zaprojektowano tak, by nie podsuwały nam widoku zawartej w nich technologii. [...] obraz ten jest tu jedynie potencjalny. Staje się on częścią pola widzenia tylko wówczas, gdy jest istotny dla obserwatora ${ }^{14}$.

${ }^{14}$ R. Arnheim, Myślenie wzrokowe, przeł. M. Chojnacki, Gdańsk 2011, s. 107-108. 
Semiosfery na poziomie użytkowania i programowania można określić jako różnosemiotyczne i wytwarzane przez odmienne kody wersje tych samych informacji tekstowych. Każda informacja tekstowa, każdy element semiosfery widoczny na ekranie poziomu użytkowania ma bowiem swoją reprezentację na poziomie programowania i odwrotnie: informacje zapisane na poziomie programowania wyświetlane są za pośrednictwem przeglądarki na poziomie użytkowania przekazu. Równocześnie jednak różny sposób organizacji semiosfer na obu poziomach, odmienny zestaw znaków, a przede wszystkim odmienna funkcja poziomu programowania i poziomu użytkowania sprawiają, że relacja ta wykracza poza prostą różnowersyjność tej samej informacji. Semiotyczna organizacja poziomu programowania $\mathrm{w}$ html głównie podkreśla strukturę dokumentu, jest przede wszystkim nośnikiem informacji dotyczących sposobu organizacji przekazu na poziomie użytkowania. Analogicznie podstawową funkcją poziomu programowania jest organizowanie przestrzeni komunikacyjnej na poziomie użytkowania, co oznacza, że semantyka tego poziomu realizuje się $\mathbf{w}$ jego syntaktyce. Tymczasem na poziomie użytkowania dominuje funkcja komunikacyjna, której podporządkowane są wszystkie inne funkcje. Trzeba tu podkreślić, iż teza ta odnosi się do mediów digitalnych jako swoistej całości; pojedyncze przekazy, formy tekstowe kreowane $\mathrm{w}$ ramach mediów cyfrowych osobno definiują własną dominantę funkcjonalną (np. funkcja informacyjna Wikipedii, komunikacyjna Facebooka, kreacyjna serwisu YouTube czy innych serwisów społecznościowych).

A zatem relacje między semiosferami obu poziomów opisać można jako relacje różnowersyjności tej samej informacji tekstowej (czy semantycznej reprezentacji) lub wewnątrzsystemowego przekładu. Każda z tych nazw relacji akcentuje nieco odmienną jej cechę. Pierwsza skupia się na równoważności semantycznej obu semiosfer, ukazując je jako formę dubletu semantycznego; druga podkreśla akt kodowania, relacyjność obu poziomów.

Posłużenie się tym samym kodem - tymi samymi znakami literowymi, cyfrowymi, diakrytycznymi w opisie każdej informacji - zarówno tekstowej, jak i okołotekstowej (np. dotyczącej kompozycji) - czyni informację o sposobie organizacji poziomu użytkowania informacją tekstową (semiotyczne zrównanie wszystkich typów informacji jest jeszcze bardziej dobitne w zapisie zerojedynkowym). Co więcej, można łatwo wykazać, że informacja strukturalna na poziomie programowania jest ważniejsza niż informacja tekstowa, co widoczne jest przede wszystkim w tym, iż nawet drobny błąd w informacji strukturalnej może sprawić, że informacja tekstowa na poziomie użytkowania przestanie być czytelna lub ulegnie za- 
sadniczej zmianie. Waga informacji strukturalnej znajduje odzwierciedlenie w trosce o jej transparentność, uporządkowanie służące ograniczeniu możliwych błędów czy szybkiemu docieraniu do określonych informacji w celu ich modyfikacji czy podmiany. Troska ta znajduje odzwierciedlenie w organizacji semiosfery: wyświetlaniu na kolorowo wyrazów odnoszących się do opisu elementów struktury, hierarchicznym układzie elementów opisu, wyodrębnieniu informacji o sposobie kodowania, informacji o nagłówku, danych dotyczących sposobu rozmieszczenia poszczególnych elementów na stronie, ich koloru, wielkości, kształtu. Jednolitość znakowa semiosfery na poziomie kodu html definiuje go jako poziom informacji na temat sposobu organizacji tekstu i dyskursu na poziomie użytkowania. Funkcja semantyczna tego poziomu wyraża się - o czym była już kilkakrotnie mowa - w jego syntaktyce - relacji, w jaką wchodzi z semiosferą na poziomie użytkowania, w dyspozycjach dotyczących sposobu organizacji tego poziomu. Własnością semiosfery digitalnej jest zatem relacyjność. Pod tym względem semiosfera digitalna realizuje cechy semiosfery jako takiej. Jak bowiem pisze Wojciech Kalaga:

Relacje stanowią podstawowe „tworzywo" i spoiwo semioprzestrzeni oraz ontologiczną infrastrukturę myśli: inferencja i interpretacja nie są w istocie niczym innym, jak dynamicznymi zespołami relacji. [...] W kategoriach rzeczywistości aktualnej semioprzestrzeń jest metaforą - ponieważ określają ją i definiują relacje, sytuuje się ona poza aktualnym czasem i przestrzenią tzw. fizyczną. W semioprzestrzeni temporalność przekłada się na zmianę, przestrzenność zaś przekłada się na sieć różnic i powiązań. [...] Każdy znak jest relacją; znaki wchodzą w relacje między sobą, tworząc dalsze relacje; te wyłaniające się relacje wchodzą w relacje z systemami interpretacji (systemami nawyków), które same współgenerują. W samej rzeczy, potencjalności nie można „zamrozič” nawet w teorii relacje zawsze generują relacje $[\ldots]^{15}$.

Specyfiką semiosfery digitalnej byłaby relacyjność różnokodowa, wyrażająca się $\mathrm{w}$ budowaniu powiązań między znakami i systemami znaków reprezentującymi różne systemy i różne dyskursy. Specyfiką semiosfery digitalnej jest także to, iż relacje te nie są relacjami między znaczeniami czy interpretacjami, ale samymi kodami - systemami generowanymi na poziomie programowania i semiosferą na poziomie użytkowania, która również nie jest jednolita, gdyż tworzą ją relacje znaków należących do różnych systemów i systemów generowanych przez różne dyskursy. Relacyjność ma tu zatem charakter nie tylko różnokodowy (kod języka programowania i kod języków etnicznych) w sferze zapisów i projekcji cyfrowych, ale też różnosystemowy (system języka etnicznego, sys-

15 W. Kalaga, Mgławice dyskursu, Kraków 2001, s. 135-136. 
temy ikoniczne, dźwiękowe, mieszane) i różnodyskursywny (najrozmaitsze dyskursy kulturowe, np. dziennikarski, handlowy, bankowy, edukacyjny, artystyczny, naukowy i popularyzacji wiedzy).

Podstawą realizacji funkcji komunikacyjnej w możliwie nieograniczonym zakresie jest materia znaku digitalnego. Niematerialna materia znaków cyfrowych sprawia, że niezależnie od zewnętrznej postaci semiotycznej - sposobu ukazywania się znaku i tekstu, wszystkie one są znakami i tekstami tego samego typu. Obraz Picassa, rękopis Prousta, zachowane filmy okresu kina niemego, artykuły prasowe czy księgi podatkowe, które w swych pierwotnych, oryginalnych wersjach są różnymi formami tekstów operujących różnymi typami znaków powiązanych $\mathrm{z}$ odmiennymi mediami i odmienną materią znaku, wprowadzone do komputera tracą swoją dotychczasową tożsamość medialną. Nie są już malowidłem, rękopisem, gazetą czy taśmą filmową. Nadal są różnymi formami tekstu (tekst ikoniczny, słowny, mieszany), reprezentującymi różne typy dyskursów (dyskurs malarski, literacki, filmowy, dziennikarski, ekonomiczny). Ich znaki nadal różnią się w sferze przedstawień, ale mają tę samą materię - wiązkę pola elektrycznego, która czyni je znakami tożsamymi bytowo. Niematerialność znaku sprzyja pozbawieniu go przynależności do jakiegoś materialnego miejsca, zwłaszcza że środowisko, w którym bytuje, również ma charakter niematerialny.

Znak i tekst mogą być swobodnie wytwarzane, przekształcane, łączone, przywoływane i wysyłane. Stają się informacją dostępną w każdej przestrzeni i czasie dla każdego użytkownika. Nie są powiązane z żadnym fizykalnym miejscem (jak architektura), „przykute” do rzeczywistości materialnej (druk do płaszczyzny strony, fresk do ściany) tak, że ich doświadczenie, jak np. dotknięcie zabytku starożytności: egipskiego czy greckiego posągu czy przedmiotów, które wówczas używano, wymaga realnej podróży do Egiptu, Grecji lub - dzięki barbarzyństwu historii - Paryża czy Londynu. Podróż, jaką się do nich odbywa za pośrednictwem medium digitalnego, jest podróżą, która fizycznie nie rusza użytkownika z miejsca. Wpisanie adresu uruchamia „wirtualną taksówkę", której dodatkowym walorem poza natychmiastowością dostarczenia na miejsce jest taniość i łatwość podróży.

Znak, tracąc dotychczasową materialność, zyskuje formę quasi-materialną - warstwę zapisu informatycznego (zero-jedynkowego). Semiosfera poziomu programowania jest swoistą warstwą podskórną, krwiobiegiem, o którym przeciętny użytkownik komputera na co dzień nie myśli i którym nie interesuje się aż do momentu, gdy coś w sferze przedstawień zaczyna przebiegać niezgodnie $\mathrm{z}$ jego wolą. Ale jest to jednocześnie warstwa konieczna, by to, co zewnętrzne, mogło zaistnieć, być przetwarzane, przechowywane i przesyłane. Jak pisze Chris Chesher: 
Od kiedy wszelkie znaki tworzone są z tego samego materiału, wszystko jest potencjalnie wymienialne. Każde znaczące, które może zostać przekonwertowane z tego, co analogowe, może być przechowywane, reprodukowane i manipulowane w domenie cyfrowej. Dane cyfrowe można kopiować bez degradacji, pozostają one niezależne od swojego medium. Mogą być kodowane kilkakrotnie, przerzucane, magicznie zmieniane przez algorytmy i wreszcie przywoływane, dekodowane i wysyłane ${ }^{16}$.

\section{Semiosfera na poziomie użytkowania}

Semiosfera na poziomie użytkowania podporządkowana jest przede wszystkim funkcji komunikacyjnej, która steruje innymi funkcjami, warunkuje je i reinterpretuje (w szczególności funkcją informacyjną, ale także perswazyjną czy estetyczną). Dominantą jest zaspokojenie potrzeb komunikacyjnych możliwie każdego typu odbiorcy. Informacja tekstowa wspierana jest dbałością o szybkie dotarcie do niej. Likwidowaniu wszelkich barier komunikacyjnych, łatwej akceptacji przekazu sprzyja dostosowanie semiosfery do przyzwyczajeń kulturowych użytkownika. Wyglądy stron internetowych są często nośnikami cech gatunkowych czy dyskursywnych przekazu. Przykładu dostarczają tu strony bibliotek cyfrowych, które zawierają elementy ikoniczne mające kojarzyć się z tradycyjną biblioteką (np. wizerunki półek z książkami), czy strony czasopism internetowych, których układ graficzny nawiązuje wyglądem do tradycyjnego czasopisma. Motywy ikoniczne, kompozycja strony pełnią dodatkowo funkcję metadyskursywną - interpretują dyskurs digitalny jako zakotwiczony w tradycyjnych, znanych odbiorcy gatunkach, formach medialnych, instytucjach, $\mathrm{np}$. wpisują stronę $\mathrm{z}$ tekstami literackimi $\mathrm{w}$ tradycję istniejących $\mathrm{w}$ przestrzeni rzeczywistej bibliotek, mimo iż zbiory cyfrowe redukują bibliotekę do tkanki tekstu, rezygnując z fizykalności książki, budynku itp. Dodatkowa semantyzacja semiosfery służy nie tylko celom czysto komunikacyjnym - szybszej identyfikacji charakteru strony, ale pełni też funkcje ideowe - ma tworzyć iluzję tożsamości, sugerować podobieństwo, ciągłość kulturową, czy dyskursywną, sprzyjać łatwiejszej akceptacji nowego medium (funkcja perswazyjna). Wykorzystuje naszą skłonność do myślenia opartego na analogii, paraleli, podobieństwie, które pozwalają ustalić tożsamość nowego przez zakotwiczenie w znanym i rozpoznanym, a tym samym oswoić i zaakceptować to, co

${ }^{16} \mathrm{Ch}$. Chescher, Ontologia domen cyfrowych, [w:] Widzieć, myśleć, być. Technologie mediów, red. A. Gwóźdź, Kraków 2001, s. 156. 
nowe. Akcentowanie podobieństwa sprzyja kamuflowaniu różnic, łatwiejszej akceptacji odmienności.

Przedstawienia ikoniczne są reprezentacjami działań. Każde przedstawienie obrazowe (napis, znak ikoniczny) może być opatrzone funkcją działania - zwłaszcza przenoszenia użytkownika do innej, często również zlinkowanej informacji lub - może lepiej - wywoływania jej. Dostrzega to Derrik de Kerckhove, gdy pisze o czasownikowym wymiarze przedstawień komputerowych:

Trzeba się jednak zastanowić, co znaczy dziś, że coś jest „obrazem”. Ikona w komputerze nie pełni funkcji rzeczownika, prostej reprezentacji, lecz czasownika. Klikasz na ikonę, a ona robi coś dla ciebie, działa ${ }^{17}$.

Wśród przedstawień obecnych na poziomie użytkowania i pełniących funkcję działań wyodrębnić można te, które powołane zostały do życia dla potrzeb działań w przestrzeni komunikacji digitalnej, oraz te, dla których funkcja działań jest funkcją dodatkową. W pierwszym przypadku są to przede wszystkim ikony znajdujące się w przestrzeni interfejsu - np. ikony umieszczone $\mathrm{w}$ paskach narzędzi. Ich znaczenie realizuje się $\mathrm{w}$ akcie działania - byciu narzędziem umożliwiającym dokonywanie określonych operacji tekstowych. W drugim przypadku są to przedstawienia obrazowe (np. napis) znajdujące się w polu tekstowym, które w sposób tradycyjny są nośnikami znaczeń, ale oprócz tego pełnią funkcję mediacyjną (są linkami). Oznacza to, iż semiosfera digitalna charakteryzuje się znaczną elastycznościa jeśli chodzi o możliwość przypisania jej różnych funkcji (np. reprezentacji znaczeń i reprezentacji działań). Ikony digitalne są wielofunkcyjne, należą jednocześnie do różnych poziomów; poziomy te porządki: tekstu i dyskursu - wzajemnie się przenikają.

Przestrzeń semiotyczna na poziomie użytkowania ma charakter synkretyczny i hybrydyczny. Na ekranie komputera współbytują, a często i łączą się obrazy znaków słownych, matematycznych, ikonicznych (symbole, grafika, przedstawienia fotograficzne, hieroglify - emotikony) chromatyczne i achromatyczne, ruchome i nieruchome. Ważny dla semiosfery cyfrowej jest aspekt dźwięku, ruchu i światła, które modelują odbiór tekstów tak pod względem estetycznym jak i znaczeniowym oraz emocjonalnym. Elementy te biorą udział w uprzestrzennieniu warstwy przedstawień tekstu (zwłaszcza dźwięk i światłocień), dzięki czemu tekst cyfrowy już na poziomie wyrażania zyskuje głębię na kształt rzeczywistości fizykalnej. Mogą też ikonizować tekst, wpisując się i przekształcając tra-

17 D. de Kerckhove, Umyst dotyku. Obraz, ciało, taktylność, fotografia, przeł. A. Maj, [w:] Kody McLuhana. Topografia nowych mediów, red. A. Maj, M. Derda-Nowakowski, Katowice 2009, s. 47. 
dycję poezji konkretnej18, narratywizować warstwę przedstawień (zwłaszcza w efekcie jej kinetyzacji), uczestnicząc w tworzeniu narracji globalnej $\mathrm{w}$ interakcji narracji kreowanej przez teksturę i narracji słownej.

Komunikację komputerową cechuje tendencja do maksymalnego semiotycznego urozmaicenia warstwy przedstawień, przy jednoczesnej tendencji do uproszczenia (redukcji) formy. Łączenie tych tendencji jest tylko pozornie antynomiczne. $\mathrm{W}$ istocie urozmaicenie semiotyczne sprzyja jednoczesnej aktywizacji rozmaitych form percepcji (wzrokowej, słuchowej, taktylnej) i form poznania (poznanie dyskursu liczbowego, słownego, obrazowego), zaś redukcja znaku (przejawiająca się np. w stosowaniu akronimów czy uproszczonych znaków ikonicznych) wpisuje się w dążenie do nieustannej symplifikacji i przyspieszania przebiegu komunikacji.

Specyfiką technologii cyfrowych jest prezentowanie postawy otwartej wobec zasobu znaków istniejących, zakotwiczonych w kulturze. Możliwości technologiczne mediów cyfrowych pozwalają na adaptację niemal każdej postaci znaku wypracowanej przez media już istniejące. To sprawia, że warstwa semiotyczna przekazów cyfrowych na poziomie użytkowania jest nieskończenie różnorodna, ale tylko z punktu widzenia dotychczasowych mediów i dotychczasowej kultury, nie zaś z punktu widzenia cyfrowości, dla której adaptacja i swobodne przetwarzanie istniejących znaków i tekstów jest jej cechą ontyczną. Przekaz cyfrowy unieważnia różnorodność materialną tekstów - wszystkie zbudowane są z tej samej niematerialnej materii. To sprawia, że $\mathrm{w}$ sferę tekstu reprezentującego określony dyskurs mogą swobodniej przenikać formy semiotyczne wiązane dotychczas z innymi sztukami (np. możliwe jest udźwiękowienie słowa literackiego, jego atomizacja, kinetyzacja, przekształcanie, ikonizacja a nawet wchodzenie w kontakt fizykalny $\mathrm{z}$ odbiorcą - tworzona jest literatura czerpiąca $\mathrm{z}$ tradycji animacji, instalacji, gry).

O specyfice warstwy przedstawień w komunikacji cyfrowej decyduje też jej interaktywny charakter. Znaczna część tekstów ukazuje się lub jest kreowana w efekcie działań użytkownika. Daje to użytkownikowi poczucie władzy nad wirtualnym światem przedstawionym, nad światem cyfrowego znaku i tekstu, zachęca do ich kreacji. Warstwa przedstawień jest kombinacją różnych znaków i czynności (zaznaczania, wstawiania, wycinania, wpisywania, montażu). Metoda „wskaż i kliknij”, niezależnie czy odnosi się do ikony, czy do słowa, według Paula Levinsona „zastępuje składnię werbalną jako strukturę poleceń - należy wskazać i kliknąć

18 Zob. A.K. Schaffner, From concrete to digital. The reconceptualization of poetic space, [w:] Beyond the Screen. Transformations of Literary Structures, Interfaces and Genres, red. J. Schäfer, P. Gendolla, Bielefeld 2010, s. 179-197. 
zamiast pisać np. «przeczytaj» albo wymieniać przypisany uprzednio numer tekstu on-line, który ma zostać odczytany [...]"19.

Warstwę przedstawień, zarówno na poziomie znaku jak i tekstu, cechuje opcjonalność - wielowersyjność. Uwidocznia się ona w tym, iż jednemu znaczeniu i działaniu (pełnionej funkcji) znaku przypisane są różne formy wyrażania: ikoniczne, algebraiczne, dźwiękowe. $\mathrm{Z}$ analogicznym zabiegiem mamy do czynienia na poziomie tekstu, gdzie dana informacja tekstowa ma przedstawienia alternatywne: słowne, graficzne, fotograficzne czy filmowe, wpisując się w kształtowanie polisemiotycznej i multimedialnej synonimii. „Obiekt nowych mediów - pisze Lev Manovich - istnieje najczęściej w wielu różnych wersjach, a nie w powtarzalnych kopiach. Ponadto owe odmienne wersje nie są w całości tworzone przez człowieka, ich automatycznym składaniem zajmuje się komputer"20. To sprawia, że bycie użytkownika w świecie digitalnym jest uczestnictwem w różnych dyskursach, w świecie tekstowym „zmieszanym”, ukonstytuowanym $\mathrm{z}$ rozmaitych, zastanych form dyskursywnych angażujących też pozatekstową fizykalnośćc1.

Własnością całej semiosfery digitalnej na poziomie użytkowania jest też jej palimpsestowość, o czym świadczy istnienie warstwy pola tekstowego oraz warstwy interfejsu. System nakładek ilustrujących wielopoziomową palimpsestowość widoczny jest w możliwości rozwinięcia w osobną kartę skrótowo zaznaczonych jednostek tekstowych czy narzędziowych.

Aspekt przedstawień i materii semiosfery na poziomie użytkowania dopełniają: funkcja semantyczna (znaczenia denotowane i konotowane) oraz funkcja działań (manipulowania tekstem czy przenoszenia do innego tekstu - mediacji). Znaczenia w przekazach komputerowych tworzone są w interakcji znaczeń słownych, ikonicznych (grafiki, fotografii) i dźwiękowych. Ważnym czynnikiem uczestniczacym w kreowaniu znaczeń jest możliwość wprawienia w ruch oraz modyfikacji każdego elementu warstwy wizualnej - elementy obrazowe (także słowa-napisy) istnieją tu na prawach materii plastycznej, którą można dowolnie kształtować. W komunikacji cyfrowej semiosfery te nie egzystują obok siebie, ale tworzą jeden system tekstowo-komunikacyjny.

Z kolei funkcja działań przekształca odbiorcę (czytelnika, widza, słuchacza) w użytkownika tekstu, czyni go jego administratorem (zarządzanie, organizowanie, tworzenie tekstu), współtwórcą, ale i koniecznym

19 P. Levinson, Miękkie ostrze. Naturalna historia i przyszłość rewolucji informacyjnej, przeł. H. Jankowska, Warszawa 1999, s. 254.

${ }^{20}$ L. Manovich, Język nowych mediów, przeł. P. Cypryański, Warszawa 2006, s. 103.

${ }^{21}$ Przykładu dostarczają tu projekty „T-Garden”, „Text Rain”. Zob. J.D. Bolter, D. Gromala, Windows and Mirrors. Interaction Design, Digital Art and the Myth of Transparency, London 2005, s. 116-129. 
inicjatorem dyskursu cyfrowego. Wśród elementów tekstowych realizujących funkcję działań w tekście i na tekście wyróżnić można mediatory oraz operatory. Funkcja mediacyjna znaków cyfrowych wyraża się w zdolności do przenoszenia użytkownika do innego znaku i tekstu - strony, dla której dany znak stanowi hasło wywoławcze.

W Sieci znaki pisma i znaki obrazu można zaprogramować jako ikony, tj. jako oznaczniki, które przez kliknięcie myszą ustanawiają na płaszczyźnie pragmatycznej już nie tylko symboliczne, ale rzeczywiste powiązanie z tym, co określają - pisze Sandbothe. - Na przykład kliknięcie myszą w filozoficznym tekście na zaprogramowaną jako link sekwencję słowną Z genealogii moralności Nietzschego wprowadza mnie bezpośrednio w tekst Nietzschego, bądź też zaprogramowany jako link portret Fryderyka Nietzschego prowadzi mnie via kliknięcie bezpośrednio na stronę Sieci z informacjami na temat jego biografii ${ }^{22}$.

Nie każdy element tekstowy (ikoniczny, słowny) jest mediatorem, choć każdy może nim być - jeśli tylko zostanie na poziomie programowania zdefiniowany jako link. Obecność funkcji mediacyjnej słowa czy ikony zaznaczona jest $\mathrm{w}$ planie wyrażania (wyróżnienie elementu tekstowego przez zapis innym kolorem, czy też podkreślenie) lub przyjęta konwencjonalnie (ikony $\mathrm{w}$ paskach narzędzi). Sygnalizowana jest też zmianą wyglądu kursora w momencie najechania na link. Dodatkowym czynnikiem uaktywniającym ten aspekt elementu tekstowego jest działanie użytkownika - kliknięcie na link.

Kolejną ważną funkcją, jaką mogą pełnić znaki cyfrowe, jest to, iż użytkownik może na ich pośrednictwem dokonywać operacji na innych znakach i tekstach. Znaki te określam jako operatory. Typowym operatorem jest znak kursora, który nie należy do tekstu, ale związany jest z dyskursem. Zarówno link, jak i kursor jako powiązane z działaniem, obecne i realizujące się w akcie interaktywnej komunikacji, określają specyfikę przekazu digitalnego.

Technologia digitalna adaptuje i przetwarza medialnie formy ukazywania się znaku i tekstu istniejące w kulturze, wykorzystuje też ukształtowane kulturowo semantyzacje barwy, kompozycji, linii czy dynamiki przedstawienia, tworząc wypowiedzi metatekstowe. I tak np. ewokowanie klarowności, uporządkowania w warstwie obrazowej przejawia się choćby w obecnej w Internecie strukturze okien - w układach linii prostych kulturowo wiązanych z klasycznością. Dążenie do nieustannej aktualizacji przekazu znajduje z kolei wyraz w odwoływaniu się do ruchu, zaś potrze-

22 M. Sandbothe, Transwersalne światy medialne. Filozoficzne rozważania o Internecie, przeł. K. Krzemieniowa, [w:] Widzieć, myśleć, być. Technologie mediów, wyb. A. Gwóźdź, Kraków 2001, s. 218. 
ba uwydatnienia znaku (emfazy) - we wzmocnieniu go motywem dźwiękowym. Komunikacja internetowa semantyzuje ponadto warstwę przedstawień w specyficzny dla siebie sposób. Zaznaczenie słowa (podkreślenie linią, innym kolorem) służy wskazaniu, że dany znak np. słowny poza tradycyjną funkcją semantyczną $\mathrm{w}$ tekście jest znakiem mediacyjnym (kliknięcie na niego przenosi użytkownika w inny tekst). Znak należy wówczas do porządku znaczeń tekstu linearnego i porządku dyskursu linkowego. Zaznaczenie jest węzłem spajającym różne teksty i porządki dyskursu (np. tekst linearny i dyskurs tworzony w wyniku przejść linkowych). Powtarzanie określonego sposobu zaznaczeń w tej samej funkcji prowadzi z kolei do trwałej semantyzacji zaznaczenia, przekształcając je $\mathrm{w}$ skonwencjonalizowany znak funkcyjny. Czyni je trwałym elementem struktury przekazu, którego przełamywanie może stać się podstawą działań artystycznych w przestrzeni digitalnej.

\section{$* * *$}

I wreszcie na koniec, warto pokusić się o krótką refleksję nad znaczeniem opisu znaku digitalnego (i przekazu digitalnego) dla badań nad literaturą. Czy można tu mówić o jakiejkolwiek przydatności? Odpowiedzi na to pytanie powinna dostarczać świadomość tego, iż znak leży u podstaw wszelkiego typu tekstów - konstytuuje też tekst literacki i za jego pośrednictwem dyskurs literatury. Jest ich budulcem. Jakiekolwiek modyfikacje w sferze znaku - jego ontyczności, budowy, funkcji skutkują modyfikacjami w sferze znaku literackiego, tekstu, dyskursu literatury (podobnie jak i w sferze każdego innego tekstu kultury).

Znaki i teksty są strukturami relacji. Nieskończonej semiozie - ruchowi od jednego znaku do drugiego w akcie odniesienia, odpowiada na poziomie tekstu intertekstualność - ruch od jednego tekstu do drugiego. Tekst literacki określić można jako „wielki znak”, strukturę relacji wielu zazębiających się, powiązanych ze sobą aspektów. Znaczenie globalne ustanawiane przez odbiorcę - jest zmienną w czasie interpretacją, znaczeniem w nieustannym ruchu, który to ruch gwarantuje życie tekstu. Jest interakcją znaczeń inicjowanych przez impulsy tekstowe: warstwę wyrażania (szczególnie silnie wykorzystywane w literaturze cyfrowej), znaczenie warstwy słownej, znaczenia innych tekstów, z którymi tekst literacki wchodzi w bezpośrednią relację, bycie reprezentacją dyskursu literatury, dyskursu sztuki, nawiązania do innych dyskursów oraz czynniki warunkujące odbiór impulsu, jak np. wiedza i wrażliwość literacka odbiorcy, intencja i działanie twórcze autora, historyczny i społeczny moment odbioru. Przesunięcia w sposobie istnienia owych impulsów i czynników mają wpływ na globalne znaczenie tekstu. 
Znak digitalny (a za nim tekst i dyskurs digitalny) jest nową jakością $\mathrm{w}$ stosunku do znaków zastanych, jakością powodującą istotne zmiany w tekście i dyskursie literackim ${ }^{23}$. Jeśli więc za chwilę przyjdzie polskim literaturoznawcom (gdyż zachodnim już przyszło ${ }^{24}$ ) rozwinąć rozpoczęte ${ }^{25}$ badania nad literaturą digitalną - nie tą zamieszczaną w mediach cyfrowych, ale tą wytwarzaną za pośrednictwem narzędzi digitalnych - poezją kinetyczną, prozą hipertekstową, to przydatna w tym działaniu może okazać się poszerzona świadomość na temat modyfikacji w sferze jednostek i struktur tekstowych. Tak jak przydatne w przypadku badań kultury ludowej okazało się dla Bachtina odwołanie do zachowań karnawałowych ${ }^{26}$, zaś w przypadku Barthesa oparcie koncepcji mitu ${ }^{27}$ jako struktury na koncepcji binarnej budowy znaku językowego de Saussure'a, tak też inspirująca dla rozpoznań w badaniach literatury digitalnej może być wiedza na temat tekstowego i dyskursywnego wymiaru linków - ich zdolności znaczeniotwórczych; czy udziału wielokodowych, ruchomych znaków i narzędzi interfejsu w kształtowaniu literatury $\mathrm{w}$ przestrzeni digitalnej.

\section{LITERATURA}

Arnheim R., Myślenie wzrokowe, przeł. M. Chojnacki, Gdańsk 2011.

Bachtin M., Twórczość Franciszka Rabelais'go a kultura ludowa średniowiecza i renesansu, przeł. A. i A. Goreniowie, oprac. S. Balbus, Kraków 1975.

${ }^{23} \mathrm{O}$ związkach między znakiem i tekstem cyfrowym zob. też J.D. Bolter, Przestrzeń pisma. Komputery, hipertekst i remediacja druku, przeł. A. Małecka, M. Tabaczyński, Kraków-Bydgoszcz 2014, s. 218-222.

${ }^{24}$ Reading Moving Letters. Digital Literature in Research and Teaching, red. R. Simanowski, J. Schäfer, P. Gendolla, Bielefeld 2010; Beyond the Screen. Transformations of Literary Structures, Interfaces and Genres, red. J. Schäfer, P. Gendolla, New Brunswick, NJ 2010; R. Simanowski, Digital Art and Meaning. Reading Kinetic Poetry, Text Machines, Mapping Art, and Interactive Installation, Minneapolis 2011; M. Eskelinen, Cybertext Poetics. The Critical Landscape of New Media Literary Theory, London-New York 2012; Regards Croisés. Perspectives on Digital Literature, red. P. Bootz, S. Baldwin, Morgantown 2010; C.T. Funkhouser, New Directions in Digital Poetry, New York-London 2012; From Homer to Hypertext. Studies in Narrative, Literature and Media, red. H. Balling, A.K. Madsen, Odense 2002.

25 Zob. np. M. Pisarski, Xanadu. Hipertekstowe przemiany prozy, Kraków 2013; U. Pawlicka, (Polska) poezja cybernetyczna. Konteksty i charakterystyka, Kraków 2012; M. Pisarski, P. Marecki, Hiperteksty literackie. Literatura i nowe media, Kraków 2011.

${ }_{26}$ M. Bachtin, Twórczość Franciszka Rabelais'go a kultura ludowa średniowiecza i renesansu, przeł. A. i A. Goreniowie, oprac. S. Balbus, Kraków 1975; zob. też: S. Żółkiewski, Bachtin i podstawowy problem semiotyki, „Pamiętnik Literacki” 1981, z. 2, s. 177.

${ }^{27}$ R. Barthes, Mit dzisiaj, [w:] tegoż: Mitologie, przeł. A. Dziadek, Warszawa 2000. 
Balling H., Madsen A.K. (red.), From Homer to Hypertext. Studies in Narrative, Literature and Media, Odense 2002.

Barthes R., Mitologie, przeł. A. Dziadek, Warszawa 2000.

Bolter J.D., Przestrzeń pisma. Komputery, hipertekst i remediacja druku, przeł. A. Małecka, M. Tabaczyński, Kraków-Bydgoszcz 2014.

Bolter J.D., Gromala D., Windows and Mirrors. Interaction Design, Digital Art and the Myth of Transparency, London 2005.

Bootz P., Baldwin S. (red.), Regards Croisés. Perspectives on Digital Literature, Morgantown 2010.

Burbules N.C., Retoryka sieci: hiperlektura oraz krytyczny poziom piśmienności, przeł. J. Mach, [w:] Ekrany piśmienności. O przyjemnościach tekstu w epoce nowych mediów, red. A. Gwóźdź, Warszawa 2008.

Burszta W.J., Książka i czytanie $w$ popkulturowym reżimie symultaniczności, [w:] Gadżety popkultury. Społeczne życie przedmiotów, red. W. Godzic, M. Żakowski, Warszawa 2007.

Chescher Ch., Ontologia domen cyfrowych, [w:] Widzieć, myśleć, być. Technologie mediów, red. A. Gwóźdź, Kraków 2001.

Eco U., Teoria semiotyki, przeł. M. Czerwiński, Kraków 2009.

Eskelinen M., Cybertext Poetics. The Critical Landscape of New Media Literary Theory, London-New York 2012.

Flusser V., Ku filozofii fotografii, przeł. J. Maniecki, red. P. Zawojski, Katowice 2004. Kuźniarz L., Piasecki M., Zarys obiektowej metodologii analizy i projektowania multimedialnego interfejsu użytkownika. <http://www.ii.pwr.wroc.pl/ piasecki/ publications/kuzniarz_piasecki_MiSSI-98.pdf>.

Gibb S., Czarne jagody, hipertekst, przeł. M. Pisarski, Kraków 2011, <http://www.ha. art.pl/hiperteksty/czarne_jagody/czarne_jagody.html>

Godzic W., Żakowski M. (red), Gadżety popkultury. Społeczne życie przedmiotów, Warszawa 2007.

Gwóźdź A. (red.), Ekrany piśmienności. O przyjemnościach tekstu w epoce nowych mediów, Warszawa 2008.

Gwóźdź A. (red.), Widzieć, myśleć, być. Technologie mediów, Kraków 2001.

Hall E.T., Ukryty wymiar, przeł. T. Hołówka, Warszawa 1997.

Hayles N.K., Stan wirtualności, przeł. J. Mach, [w:] Ekrany piśmienności. O przyjemnościach tekstu w epoce nowych mediów, red. A. Gwóźdź, Warszawa 2008.

Kalaga W., Mgławice dyskursu, Kraków 2001.

Kerckhove D. de, Umyst dotyku. Obraz, ciało, taktylność, fotografia, przeł. A. Maj, [w:] Kody McLuhana. Topografia nowych mediów, red. A. Maj, M. Derda-Nowakowski, Katowice 2009.

Kuźniarz L., Piasecki M., Zarys obiektowej metodologii analizy i projektowania multimedialnego interfejsu użytkownika, http://www.ii.pwr.wroc.pl/ piasecki/publica tions/kuzniarz_piasecki_MiSSI-98.pd.

Levinson P., Miękkie ostrze. Naturalna historia i przyszłość rewolucji informacyjnej, przeł. H. Jankowska, Warszawa 1999.

Łotman J., Uniwersum umysłu. Semiotyczna teoria kultury, Gdańsk 2008. 
Maj A., Derda-Nowakowski M. (red.), Kody McLuhana. Topografia nowych mediów, Katowice 2009.

Manovich L., Język nowych mediów, przeł. P. Cypryański, Warszawa 2006.

Pawlicka U., (Polska) poezja cybernetyczna. Konteksty $i$ charakterystyka, Kraków 2012.

Pisarski M., Nowe media - nowe opowieści? Fabułotwórczy potencjał struktur hipertekstowych, [w:] Przekaz digitalny. Aspekty semiotyczne, semantyczne i komunikacyjne, red. E. Szczęsna, Kraków 2015.

Pisarski M., Xanadu. Hipertekstowe przemiany prozy, Kraków 2013.

Pisarski M., Marecki P., Hiperteksty literackie. Literatura i nowe media, Kraków 2011.

Sandbothe M., Transwersalne światy medialne. Filozoficzne rozważania o Internecie, przeł. K. Krzemieniowa, [w:] Widzieć, myśleć, być. Technologie mediów, wyb. A. Gwóźdź, Kraków 2001.

Schäfer J., Gendolla P. (red.), Beyond the Screen. Transformations of Literary Structures, Interfaces and Genres, New Brunswick, NJ, 20102010.

Schaffner A.K., From concrete to digital. The reconceptualization of poetic space, [w:] Beyond the Screen. Transformations of Literary Structures, Interfaces and Genres, red. J. Schäfer, P. Gendolla, Bielefeld 2010.

Simanowski R., Digital Art and Meaning. Reading Kinetic Poetry, Text Machines, Mapping Art, and Interactive Installation, Minneapolis 2011.

Simanowski R., Schäfer J., Gendolla P. (red.), Reading Moving Letters. Digital Literature in Research and Teaching, Bielefeld 2010;

Szczęsna E. (red.), Przekaz digitalny. Aspekty semiotyczne, semantyczne i komunikacyjne, Kraków 2015.

Żółkiewski S., Bachtin i podstawowy problem semiotyki, „Pamiętnik Literacki” 1981, z. 2. 